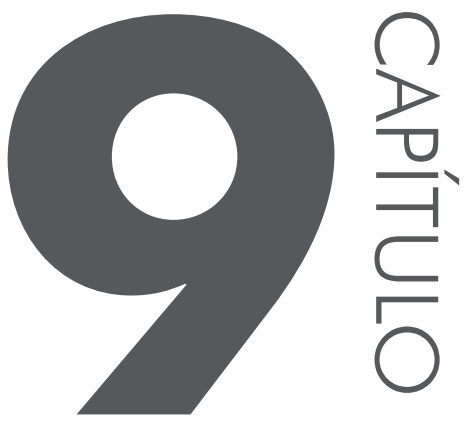

\title{
AS BASES TRADICIONAIS DA EXPERIÊNCIA NEOLIBERAL NO CEARÁ: A FORÇA ELEITORAL DOS CLÃS POLÍTICOS FAMILIARES
}

Cristiane Maria Marinho ${ }^{1}$ Maria Cristina de Queiroz Nobre ${ }^{2}$

\subsection{INTRODUC̣ÃO}

1 Pós-doutora em Filosofia da Educação pela Universidade Estadual de Campinas (Unicamp). Professora de Filosofia da Universidade Estadual do Ceará. Contato: c-marinho2004@ig.com.br, (85) 3226-0147.

2 Doutora em Sociologia pela Universidade Federal do Ceará (UFC). Professora do Curso de Serviço Social e do Mestrado Acadêmico em Serviço Social, Trabalho e Questão Social da Universidade Estadual do Ceará e coordenadora do Laboratório de Pesquisas e Estudos em Serviço Social / CESA. Contato: cristina.nobre@uece.br, (85) 3232-3939. 
Em função de grandes secas, clima instável, descaso político, dependência econômica e política, dentre outras questões, há no Ceará uma economia periférica em relação ao Sul do país e, por sua vez, ao capital estrangeiro. Pode-se, por isso, afirmar que tem sido uma economia dependente, desde o início da colônia até a atual fase republicana, e marcada por um capitalismo também periférico e dependente.

Dessa forma, é possível compreender que nesse contexto a estrutura das elites políticas e econômicas sempre se mostrou frágil, significando muitas vezes a impossibilidade da sua permanência continuada no governo do Estado ou na hegemonia política local: "Daí a alternância das facções da classe dominante no poder ou a formação de grandes coligações, bem como a grande influência da política cearense sobre o que se passava nacionalmente - os fatos políticos e econômicos nacionais repercutiam no Estado, visto que as divergentes elites locais não tinham condições de se opor em bloco" (FARIAS, 2012, p. 370). Assim, a alternância de grupos no poder e as coligações são significativas da frágil estrutura das nossas elites.

Ainda segundo Farias (2012, p. 371), a fragilidade estrutural das elites cearenses fez com que até mesmo as maiores oligarquias tivessem de "se coligar com outros grupos políticos menores para ganharem as eleições ou mesmo governarem o Estado". Evidencia-se nessas elites, portanto, a ausência de uma ideologia comprometida com a coletividade, bem como a necessidade de se fazer coligações para a permanência no poder. Tais coligações implicam acordo com desfecho incerto na medida em que sempre há o risco de traição e disputas sobre a ocupação dos cargos mais importantes. Contudo, esses acordos são necessários no âmbito da fragilidade das elites cearenses, pois evitam "as desgastantes disputas entre as facções políticas maiores e afasta-se a possibilidade de mudanças da ordem socioeconômica e/ou a divisão do poder com grupos emergentes. São, em geral, acordos de cúpulas, que não levam em conta as necessidades da população" (FARIAS, 2012, p. 377).

A debilidade da elite cearense se mostra mais evidente se considerarmos, por exemplo, que ela nunca apresentou oligarquias fortes e influentes como aconteceu na região açucareira de Pernambuco e da Bahia. Pelo contrário, diz-nos Farias (2012, p. 389), "um traço peculiar das elites cearenses foi sua debilidade estrutural", forçada a diversas coligações para se manterem no poder.

As coligações sempre tiveram presentes na história cearense, mas destaque-se aqui apenas a década de 1970, período coberto pela nossa pesquisa, e que é muito representativo desta reflexão sobre a fragilidade das elites cearenses obrigadas a apoiar em coligações. Foi então marcante a presença dos três grupos oligarcas de coronéis na política do Estado: Virgílio Távora, Adauto Bezerra e César Cals. 
Sobre a dependência, fragilidade e coligações em torno desses grupos, assim se manifesta Farias (2012, p. 404):

\begin{abstract}
Não havia um grupo político local forte o suficiente para impor seu domínio sozinho. $\mathrm{Na}$ realidade, o próprio controle que os coronéis exerciam sobre o Ceará decorria, sobretudo, de um fator externo, isto é, o apoio que recebiam da ditadura militar brasileira. Com o centralismo político imposto no país após 1964, a escolha dos grupos dominantes estaduais passava pela aprovação do regime militar, circustancias que as fracas elites locais aceitaram ou foram obrigadas a aceitar.
\end{abstract}

O Acordo dos Coronéis, como ficou conhecido historicamente, é representativo da impossibilidade de a elite cearense protagonizar o poder de forma solitária. Daí a formação de um pacto, o rodízio de seus componentes no poder e as grandes coligações que deram sustentação à sua longa permanência no governo estadual, de forma a que o poder não se dividisse com outros grupos emergentes e fosse adiante o processo de modernização conservadora pautada na industrialização promovida por esses grupos.

Dessa forma, a questão que se coloca aqui, como um dos nortes da pesquisa que estamos apresentando, é a de que forma essa característica de fazer coligações das elites dirigentes cearenses, em função de sua fragilidade, permanece no período seguinte ao do Acordo dos Coronéis, em fins da década de 1980, que passa a ser comandado pelo representante do projeto burguês industrial, Tasso Jereissati, nascido no seio do Centro Industrial do Ceará (CIC) em uma suposta perspectiva de superação da política anterior dos coronéis. Como vamos observar, em termos de necessidade de existência de coligações para a sustentação de poder, não houve muita diferença.

Tem-se ainda que saber em que bases as coligações permanecem nesse "novo" contexto político e econômico do ciclo de poder conhecido como "Era Tasso". Tais coligações, além de viabilizarem as diversas vitórias eleitorais que mantiveram o grupo de empresários do CIC no poder, deram as condições para a realização de um conjunto de medidas que inauguraram no Brasil o processo de contrarreforma neoliberal com sua perspectiva modernizante da máquina burocrática e que em alguns momentos tencionam as bases da política clientelista tradicional (Cf. NOBRE, 2008).

De fato, os governos da "Era Tasso" se caracterizaram pelo esforço em modernizar a máquina burocrática por meio de medidas que depois se tornaram clássicas na experiência neoliberal em termos nacionais, tais como ajuste fiscal, redução do quadro funcional a partir da extinção e fusão de secretarias e setores diversos e da terceirização de serviços. Tudo isto teve como efeito a redução do gasto com funcionalismo, o que também foi ajudado pela contenção salarial. $\mathrm{Na}$ medida em que se concretizaram as condições legais em âmbito nacional para a 
contrarreforma, os governos locais puderam reduzir ainda mais os gastos com pessoal mediante adoção de suas novas regras para a previdência cearense. O resultado geral foram as novas condições financeiras e administrativas que levaram a cabo um processo de modernização conservadora responsável pelo crescimento econômico do Ceará, manutenção de sua histórica desigualdade social e das mesmas estruturas asseguradoras da extrema concentração fundiária.

No âmbito das políticas sociais, os governos da "Era Tasso" se propuseram a superar o histórico assistencialismo desenvolvido no período de Virgílio Távora, coordenado pela primeira-dama Luíza Távora, a Mãe dos pobres, e sua relação com o fortalecimento e favorecimento das coligações voltadas para a compra de votos. Nessa perspectiva, os governos do novo ciclo de poder destacam-se pelo trabalho desenvolvido na Secretaria de Ação de Social, o qual tinha o claro objetivo de formar novas lideranças comprometidas com o governo, infiltrar o governo nos movimentos populares, diminuir a penetração das esquerdas nos movimentos populares, preparar terreno para a futura eleição e favorecer as coligações já realizadas e de sustentação do governo (Cf. FARIAS, 2012, p. 432). Na mesma linha, os chamados "Governos das Mudanças buscaram criar novas relações com os movimentos sociais, as comunidades locais e suas associações por meio do Projeto São José, que financia os projetos de infraestrutura e de atividades produtivas diretamente para organizações populares, buscando romper com a dependência de políticos locais.

Nos dois casos, no assistencialismo e na intermediação por lideranças políticas de recursos públicos para obras locais, estão postos os mesmos mecanismos que resultam nas trocas do favor por votos e acabam por manter a frágil política, precisamente o que os Governos das Mudanças prometeram erradicar. Entretanto, esses governos não conseguiram avançar em suas propostas modernizantes e, ao mesmo tempo, romper com as antigas bases da política local, tendo que manter as mesmas coligações e alianças políticas dos seus antecessores. Em outros termos, foram governos que implementaram as políticas modernizantes de caráter neoliberal em consonância com a velha política, ainda que tenham utilizado novos recursos políticos e novas estratégias eleitorais e de governo que diferem do modo tradicional de conquistar apoio político, bem como tenham se sustentado no discurso de superação do velho clientelismo.

Contudo, estas últimas questões precisam ser mais bem desenvolvidas ao longo da nossa pesquisa. No momento vamos apresentar somente a continuidade das coligações nos governos da Era Tasso, constatando a predominância da tradicional característica de se proceder a coligações das elites cearenses para ir além de sua fragilidade e permanecer no poder. O que se torna relevante é o fato de que, em suas bases de apoio político, encontra-se a predominância de clãs políticos familiares como representação da força da política local. 


\subsection{OBJETIVOS E ASPECTOS METODOLÓGICOS DA PESQUISA SOBRE OS CLÃS POLÍTICOS NO CEARÁ}

Em nossa pesquisa, estamos nos concentrando nos dados que revelam a força eleitoral de clãs políticos familiares nas décadas de 1970 a 2010. O objetivo foi obter um mapeamento desses clãs que têm dominância na política local e caracterizar sua irradiação para a política em âmbito estadual em momentos diversos: o da Ditadura Militar, o da retomada dos direitos políticos e o de constrangimentos à democracia dado o caráter conservador do projeto neoliberal.

Nossa pesquisa consistiu em levantamento documental e bibliográfico sobre os clãs familiares a partir dos relatórios e mapas eleitorais gerados pelo Tribunal Regional Eleitoral (TRE). Nesse momento, identificamos os membros de clãs que participaram dos processos eleitorais de 183 municípios cearenses (excetuando-se Fortaleza) para prefeito e para vereadores, com análise de seus desempenhos em cada eleição. Ao mesmo tempo, a pesquisa também se voltou para a visualização da trajetória dos políticos cearenses eleitos para a Assembleia Legislativa e para a Câmara Federal que iniciaram sua carreira política nas Prefeituras em virtude da dominância política do clã familiar a que pertencem. Nessa fase, fizemos pesquisas em banco de dados de instituições públicas que reúnem informações relevantes sobre a política cearense, tais como: a Assembleia Legislativa do Estado do Ceará e a Associação dos Prefeitos do Estado do Ceará, e ainda nos principais jornais locais. Essa coleta de informações também foi enriquecida com dados captados de páginas virtuais de conteúdo político dos jornais O POVO e Diário do Nordeste. Nossa pesquisa também se pautou em estudo bibliográfico sobre a política no Ceará, em especial obras capazes de contribuir para a reconstrução histórica dos clãs familiares, como as biografias de personalidades públicas e estudos de analistas políticos do período histórico estudado.

Nossa expectativa é que essa pesquisa possa contribuir para estudos sobre a força dos grupos políticos tradicionais e sua persistente presença em fases diversas da história política cearense. A pretensão é que, ao contribuir com novas determinações da dinâmica política local, possamos encontrar subsídios para a superação dessa realidade particular e suas irradiações sobre o conjunto da sociedade. Por sua vez, o que motivou tal estudo é o pressuposto de que a permanência da política tradicional na esfera local tem impacto sobre o resultado e a eficiência das políticas sociais. Mantemos, assim, como horizonte de novas pesquisas, a preocupação de, ao mapear os clãs familiares atuantes no Ceará, podermos analisar o alcance de suas práticas na conformação das políticas sociais, em especial, sobre a política de assistência social nas últimas décadas com a criação do Sistema Único da Assistência Social (SUAS), haja vista que a área social tem sido tradicionalmente utilizada para fins clientelistas voltados para a reprodução da força política de grupos no poder. 


\subsection{ALTERAÇÕES NA POLLÍTICA CEARENSE A PARTIR DA REDEMOCRATIZAC̣ÃO}

$\mathrm{Na}$ esteira do processo de redemocratização do Brasil, na transição da década de 1970 para de 1980, a política cearense passou por mudanças significativas. De um lado, verificou-se a recuperação de forças de setores democráticos com a abertura política, o retorno do exílio e das prisões de antigas lideranças, a legalização de partidos de esquerda e a criação de novos. Por sua vez, identificamos nesse período a emergência de movimentos sociais populares nos bairros e sua organização em frentes mais amplas (Federação de Bairros e Favelas, Jornada de Luta contra e, depois, estruturada na União das Comunidades da Grande Fortaleza), a rearticulação do movimento sindical e maior visibilidade da luta pela reforma agrária, que havia resistido, nos difíceis anos, graças à Igreja Católica por meio de suas pastorais sociais. De outro lado, era a própria sociedade cearense que havia mudado como consequência do crescimento urbano. Este decorreu tanto da industrialização, que se acelerou nos anos 1970 encorado no fundo público, quanto pela continuidade dos processos migratórios devido à persistência das secas periódicas em contexto de concentração fundiária.

Nesse novo cenário, os processos eleitorais vão ganhando novos contornos. Ainda nas disputas pelo governo estadual de 1982, quando a oposição ao regime militar conseguiu eleger 10 dos 22 governadores, o Partido do Movimento Democrático Brasileiro (PMDB) obteve grande votação em Fortaleza para o seu candidato majoritário, Mauro Benevides, embora tivesse sido derrotado pelos votos do interior do Estado. Tinha-se, já naquele momento, o indício de que o eleitorado urbano passava a tencionar as antigas relações clientelistas que sustentavam a política tradicional.

Em dois momentos posteriores, essa realidade vai se ampliando. Primeiro, com a eleição em 1985 de Maria Luiza Fontenele para a Prefeitura de Fortaleza pelo ainda jovem Partido dos Trabalhadores (PT), sendo esta cidade a primeira conquista de uma capital por esse partido. Segundo, com a eleição de Tasso Jereissati para o governo estadual em uma frente de centro-esquerda comandada pelo PMDB, o que ocorreu em um confronto direto com antigas lideranças tais como as dos três últimos governadores (Virgílio Távora, César Cals e Adauto Bezerra).

Essas eleições de 1985 e 1986 apresentam também novas determinações. A partir daquele momento tornaram-se decisivos os recursos do marketing político, construindo imagens e modelando discursos, e das pesquisas eleitorais como base para a elaboração de estratégias políticas de conquista de votos (OLIVER COSTILLA; NOBRE, 2012). Com essas novas condições políticas, havia que se perguntar sobre a permanência ou não de elementos da política tradicional e como esta se conformava nos processos eleitorais do novo período democrático. 


\subsection{A DOMINÂNCIA POLÍTICA DOS CLÃS FAMILIARES NA "ERA TASSO"}

Em um esforço de investigação sobre a "Era Tasso" (NOBRE, 2008), pudemos perceber claramente como a relação entre o novo na política e a permanência do tradicional se conjugam com toda a expressividade. De fato, os governantes daquele período histórico, que compreende os três governos de Tasso Jereissati e o de Ciro Gomes (de 1987 a 2002), apoiaram-se fortemente nos novos recursos do marketing político. Da mesma forma, buscaram produzir novas lideranças e alianças políticas sintonizadas com seu projeto de modernização da estrutura estatal como suporte local à expansão capitalista em tempos de transnacionalização do capital.

A despeito dos esforços realizados na modernização da estrutura burocrática do Estado, em muitos momentos contrariando interesses de antigas lideranças políticas e suas tradicionais práticas, os governos da Era Tasso tiveram em sua base de apoio $52,70 \%$ de deputados estaduais oriundos de clãs familiares (NOBRE, 2008, p. 196.). Em vários casos, os clãs familiares marcaram presença no poder legislativo estadual com mais de um deputado do mesmo clã. Em seu conjunto, os deputados que apoiavam os chamados Governos das Mudanças demonstravam também muita força política, na medida em que $82,43 \%$ deles tiveram mais de um mandado, sendo mais expressivo o fato de que $16,22 \%$ estiveram em todos os cinco mandatos do período: eleitos entre 1986 e 1998 (NOBRE, 2008, p. 190-191).

Quanto à realidade da política municipal, identificamos que em 45,66\% dos municípios cearenses houve a dominância de um ou dois clãs familiares nas eleições de 1988 a 2004, período que corresponde àquele ciclo político. O impacto dessa dominância política está indicado também no fato de em $71,74 \%$ dos municípios cearenses ter se verificado o predomínio de uma única liderança na política local, enquanto em $21,74 \%$ isso se deu a partir de duas lideranças (NOBRE, 2008, p. 189-190).

Mesmo considerando apenas o período eleitoral que corresponde à Era Tasso (1980-1990), aquela pesquisa possibilitou a identificação de 89 clãs com forte dominância municipal. Desse total $65,16 \%$ chegaram a vencer três das cinco eleições municipais, $25,84 \%$ foram vitoriosos em quatro e $6,74 \%$ obtiveram êxito em todas as eleições de municipais desse vasto período (NOBRE, 2008, p. 196). Estão incluídas, nessa última situação, as seguintes famílias: Martins de Carnaubal, Rodrigues de Catarina, Pinheiro de Jaguaribe, Rocha de Morrinhos, Pinho de Poranga e Osterno, de Marco.

Com o balanço das eleições estaduais e municipais da "Era Tasso" pode-se constatar a permanência de traço fundamental da cultura política brasileira nesse 
período histórico, conformando os próprios interesses modernizantes da elite empresarial que ascendeu ao poder com Tasso Jereissati. Por sua vez, foi possível revelar como a influência na política local está estreitamente articulada com a condução da política no Estado como um todo a partir da relação do poder legislativo com o executivo estadual.

$\mathrm{Na}$ medida em que a referente pesquisa teve um marco temporal limitado, restrito à "Era Tasso", tornou-se relevante aprofundar o estudo sobre a dominância dos clãs familiares no Ceará em período anterior àquele ciclo de poder (nas eleições da década de 1970), e também como tal dominância se configurou em novo cenário político, o da realização de outro ciclo de poder hegemônico agora sob o comando de um clã familiar: Ferreira Gomes.

\subsection{A DOMINÂNCIA POLÍTICA DOS CLÃS FAMILIARES NO CEARÁ: DA ESFERA MUNICIPAL PARA A ESTADUAL}

A partir da pesquisa da "Era Tasso", quando identificamos clãs familiares com ascendência do poder municipal para o poder legislativo estadual durante as eleições de 1986 a 1998, buscamos fazer uma atualização incorporando os dados das eleições municipais de 2000, 2004 e 2008 e as estaduais de 2002, 2006 e 2010. Portanto, aprofundamos a pesquisa anterior ao incorporar novas informações sobre alguns dos clãs políticos familiares que marcaram presença desde o ciclo de poder dos empresários e sobre seus desempenhos nas eleições posteriores.

Ampliando a pesquisa, e ainda em termos de amostra dos municípios cearenses, partimos daqueles casos que demonstravam grande dominância no poder municipal na "Era Tasso" e podemos perceber um quadro ainda mais significativo. Em Carnaubal, a família Martins venceu 66,7\% das eleições entre 1972 e 2008, ficando durante cinco mandatos consecutivos à frente do poder municipal. Nas ocasiões em que esteve ausente dessa esfera de poder (1972, 1982 e 2008) foi substituída por membros da família Chaves. No caso do município de Catarina, a família Rodrigues está na administração municipal em seis mandatos seguidos, tendo vencido as eleições de 1988 até a de 2012, além de outro mandato conquistado em 1976. Isso representa vitórias em 77,8\% das eleições do período. Esse desempenho também é repetido pelo clã Pinheiro em Jaguaribe que só ficou ausente do poder municipal nas eleições de 1972 e 1982. O mesmo percentual de vitórias eleitorais no período estudado é registrado também para a família Osterno no município de Marco, sendo que conseguiu estar à frente do executivo durante sete mandatos consecutivos, o que foi fundamental para eleger o deputado Francisco Rogério Osterno Aguiar, como veremos mais adiante. Em Morrinhos, o clã Rocha conseguiu ficar no poder a partir da eleição de 1988 até a de 2004; foram 
cinco vitórias consecutivas, representando $55,6 \%$ do total realizado no período. O caso mais exemplar de força política está representado pelo clã Pinho, que, ao longo dessas décadas, só não fez prefeito em Poranga na eleição de 1976, sendo que o líder mais destacado é Abdoral Eufrasino de Pinho: quatro mandados de prefeito naquele município.

No âmbito deste trabalho, interessa destacar as informações sobre alguns deputados estaduais que pertencem a clãs familiares e fizeram parte da base de apoio dos Governos das Mudanças, embora o período de análise se estenda àquele ciclo de poder. Por sua vez, alguns dados biográficos sobre cada deputado e sua herança política familiar foram retirados da coleção Deputados Estaduais publicada pela Assembleia Legislativa do Ceará, Edições INESP, entre 1999 e 2006.

Em termos do poder legislativo cearense alguns casos chamam atenção pela presença, em várias eleições seguidas de representações parlamentares do mesmo clã político familiar naquela casa. Incluem-se como a expressão de maior dominância desses clãs familiares na "Era Tasso":

1) Antônio Leite Tavares: foi eleito deputado estadual em 1982, 1986, 1990 e 1994. Após sua indicação para o Tribunal de Contas do Estado (TCE), por Tasso Jereissati, seu filho, Marcos Tavares, passou a desempenhar o mandato de deputado estadual, sendo eleito em 1998 e 2002. Este clã familiar representa, ao todo, seis (6) mandatos consecutivos na Assembleia Legislativa. Ainda em 1988, Antônio Tavares renunciou ao mandato parlamentar para ser prefeito do município de Barro. Naquele município a família Tavares ocupou, desde 1972, o executivo em seis mandatos. Esse mesmo clã possui também influência em município próximo, de Abaiara, com outros três mandatos no executivo. Nesta última cidade, desde 1996, têm predominado candidatos eleitos do clã Sampaio, com quatro mandados consecutivos e outro em 1976;

2) Alexandre Figueiredo: seu pai, Francisco Figueiredo de Paula Pessoa, foi eleito deputado estadual em 1978 e 1982 . Nos dois mandatos seguintes a vaga na Assembleia foi ocupada por Alexandre (nas eleições de 1986 e 1990). Quando também foi indicado para o Tribunal de Contas do Estado (TCE), por Ciro Gomes, assume Cândida Figueiredo para mais três mandatos, com eleições em 1994, 1998 e 2002. Por último, no pleito eleitoral de 2006, foi eleito Tomás Figueiredo Filho também para aquela casa, enquanto em 2010 teve votação para suplente de deputado federal. O clã familiar esteve presente na Assembleia Legislativa, de forma consecutiva, por oito (8) mandatos, representando quase 30 anos naquela esfera do poder político. Por sua vez, esse clã familiar, o mesmo do senador 
Paula Pessoa, exerce forte liderança em Santa Quitéria, onde Tomás Albuquerque de Paula Pessoa esteve em três mandatos na prefeitura daquela cidade (eleito em 1992, 2000 e 2004);

3) Carlos Cruz: um dos mais antigos “caciques políticos” de Juazeiro do Norte, com duas passagens na prefeitura daquela cidade (eleições de 1988 e 2004), foi eleito para quatro mandatos de deputado estadual, em 1978, 1982, 1994 e 1998. Após sua saída daquela casa, assumiu sua filha Ana Paula Cruz, com mandatos conseguidos nas eleições de 2002 e 2006. Neste último, esteve na suplência, mas assumiu o mandato nos primeiros meses do ano legislativo;

4) Ciro Ferreira Gomes: outro líder político da "Era Tasso", antes de seu mandato de governador e de carreira política em âmbito nacional. Foi eleito deputado estadual em 1982 (suplente) e 1986. Neste último mandato, não completado porque se afastou da Assembleia Legislativa para disputar as eleições para a Prefeitura de Fortaleza, foi o líder do governo naquela casa. Nas duas eleições seguintes, em 1990 e 1994, foi eleito para deputado estadual o seu irmão, Cid Ferreira Gomes, atual governador do Ceará em seu segundo mandato. Cid Gomes também se afastou da Assembleia para ocupar, por duas vezes, a administração municipal de Sobral e foi substituído por outro irmão, Ivo Ferreira Gomes, eleito em 2002, 2006 e 2010. Este clã familiar, que ocupa o poder legislativo há sete mandatos, também tem fortes raízes políticas em Sobral, cuja administração já fora ocupada pelo pai dos três deputados, José Euclides Ferreira Gomes, além do fato espetacular de dois irmãos terem sido eleitos para governar o mesmo estado federativo em tão curto espaço de tempo. Ainda representando a força do clã Ferreira Gomes está Patrícia Saboya que foi casada com Ciro Gomes. Ancorada na influência do marido, aliança mantida mesmo depois do fim do casamento, Patrícia foi eleita vereadora, deputada estadual (ocupando mandato atualmente) e senadora em 2002. Ela é neta do senador cearense Plínio Pompeu Saboya;

5) Maria Lúcia Magalhães Corrêa foi eleita para deputada estadual em quatro momentos (1978, 1986, 1990 e 1994), seguida pela filha, Inês Arruda, para mais dois mandatos (nas eleições de 1998 e 2002) e a neta, Lívia Arruda em 2006. O clã também tem participação em três administrações municipais no período estudado: 1982, com o marido de Maria Lúcia (Danilo Correa), o genro Gerardo Arruda (1996) e a filha Inês em 2004. Além da presença na administração de Caucaia, da presença na Assembleia Legislativa em sete mandatos, o clã também participa da Câmara Federal com Gerardo Arruda; 
6) Francisco de Paula Rocha Aguiar, eleito para cinco mandatos no legislativo cearense (1986, 1990, 1994, 1998 e 2002), sucedendo a seu pai, o ex-deputado Murilo Aguiar (eleito em 1947, 1958, 1962, 1966 e 1982). Este clã familiar tem forte presença na política de Camocim, com vários mandatos no poder executivo daquela cidade: Murilo Aguiar (eleito em 1954), Murilo Rocha Aguiar Filho (1988) e Sérgio Aguiar (vitorioso nas eleições de 1996 e 2000). O próprio pai de Murilo Aguiar, o Coronel Moyses Cavalcante Rocha, também fora prefeito de Camocim. Mais recentemente, nas eleições de 2004 e 2008, o clã Aguiar sofreu duas derrotas na disputa municipal para Francisco Maciel Oliveira (PP), conhecido como Chico Vaulino. Na primeira eleição a disputa foi com Antônio Alberto Rocha Aguiar (irmão do ex-deputado Francisco de Paula Rocha Aguiar) e a segunda com Mônica Aguiar (esposa do ex-prefeito Sérgio Aguiar). O irmão do Deputado Murilo Aguiar, Francisco Rocha Aguiar, foi eleito prefeito de Ipu em 1966 e em 1972 elegeu sua esposa para o mesmo cargo: Maria Antonieta Rocha Aguiar. Francisco Rocha Aguiar também foi deputado estadual por um mandato (1979/1983). Dando continuidade ao clã na esfera do poder legislativo estadual, identificamos Sérgio Aguiar (filho de Francisco de Paula Rocha Aguiar), que está em seu segundo mandato de deputado estadual (eleições de 2006 e 2010). Em seu conjunto, o clã Aguiar tem estado presente na Assembleia Legislativa por 13 mandatos consecutivos;

7) Francisco Rogério Osterno Aguiar, atualmente no seu quarto mandato, e a irmã, a ex-deputada Shylene Aguiar, com um mandato naquela casa. O próprio deputado Rogério Aguiar ocupou o cargo de prefeito de Marco antes de ser eleito para a Assembleia Legislativa, além de outros mandatos de prefeitos exercidos por parentes seus naquela cidade, como já referido, com comando político desde 1976 (naquele ano foi eleito prefeito Guy Neves Osterno). Mais recentemente, foram prefeitos de Marco, o seu irmão (José William Osterno Aguiar) em 1996, um primo (Jorge Stênio Osterno) em 2000 e 2004 e outro parente, Geraldo B. Osterno Aguiar (também eleito prefeito em 1982), que sucedeu a Rogério Aguiar em 1992. Além disso, o seu filho (Francisco Rogério Osterno Aguiar Filho) foi vice-prefeito daquela cidade em 1996 e 2000;

8) Manoel Duca da Silveira Neto, eleito cinco (5) vezes para a Assembleia Legislativa, tendo renunciado ao mandato em 2005 para exercer o de prefeito de Acaraú. Manoel Duca já havia sido prefeito daquela cidade de 1977 a 1983, além de outros três mandatos exercidos por seus parentes: 
o avô Manoel Duca da Silveira, o tio Geraldo Benone da Silveira, e seu irmão Aníbal Ferreira Gomes que está em seu quinto mandato de deputado federal. Este clã familiar tem grande ascendência no poder legislativo cearense, com mandatos exercidos por seu avô, José Filomeno Ferreira Gomes, em 1947 e 1951, pelo seu pai, Amadeu Ferreira Gomes, em 1958 e 1962, e um tio, Orzete Filomeno Ferreira Gomes, que foi deputado estadual em 1970, 1974, 1978 e 1982. Assim, contabilizando somente o período mais recente, o clã completou nove (9) mandatos consecutivos naquela casa, além dos outros quatro (4) exercidos pelo pai e avô. O próprio deputado Manoel Duca esteve envolvido em disputa política de seu clã familiar, em episódio em que seu primo, João Jaime Ferreira Gomes, que estava exercendo o mandato de prefeito, foi assassinado. O ex-deputado, junto com dois irmãos, foi acusado do referido assassinato que teria beneficiado um de seus irmãos no comando do executivo municipal de Acaraú, Amadeu Ferreira Gomes, que depois acabou renunciando. O ex-deputado Manoel Duca também é acusado de envolvimento no crime de Afonso Henrique Fontes Neto, que disputou a eleição para deputado federal em 1986;

9) a família Arruda, do município de Granja, com cinco décadas à frente do poder local tem ascendência também na política estadual. Dessa família fazem parte o ex-deputado federal, suplente de senador pelo PSDB e atual prefeito de Granja: Esmerino Coelho Arruda; o seu irmão e deputado federal Vicente Arruda; o atual deputado estadual Esmerino Arruda Coelho Filho, conhecido por Gony Arruda, que está em seu terceiro mandato. Gony Arruda é filho também de Carmem Sales Oliveira Arruda, duas vezes prefeita do mesmo município e sobrinho de Eliezer Oliveira de Arruda Coelho Filho, prefeito eleito em 1992, intercalando os mandatos de Esmerino Arruda e Carmem Arruda. O pai de Esmerino e Eliezer Arruda, Eliezer Oliveira de Arruda Coelho, também foi eleito prefeito de Granja em 1972 e 1982 e eleito na suplência de deputado estadual em 1978;

10) a família Girão, de Morada Nova, da qual faz parte o ex-deputado, por dois mandatos, Francisco Xavier Andrade Girão. Franciné Girão, como é conhecido, conduziu o executivo daquele município por três vezes (eleito em 1982, 1996 e 2000). O seu pai, Perboyre Teófilo Girão já havia sido prefeito daquela cidade, enquanto seu irmão Francisco Andrade Teófilo Girão foi eleito vereador em 1970 e deputado estadual em 1982 e 1987. Após a morte prematura deste último, em 1988, sua mulher, Maria Auxiliadora Damasceno Girão, foi eleita prefeita, sucedendo a Franciné Girão, 
enquanto o filho do casal, Adler Damasceno Girão, foi também eleito prefeito em 2004. Em seu conjunto, a família Girão completou seis (6) mandatos no executivo municipal, sofrendo derrotas em 1992 e 2008 para Glauber Barbosa Castro;

11) a família Azevedo de Trairi, com cinco mandatos consecutivos no executivo municipal: Jonas Henrique Azevedo (eleito em 1982 e 1992) e Henrique Mauro de Azevedo Porto (1988, 1996 e 2000), além das seguidas vezes em que o ex-deputado José Henrique Azevedo foi eleito suplente de deputado estadual, tendo assumido o mandato nas quatro ocasiões em que isto ocorreu. Nas eleições municipais de 2008, Henrique Mauro de Azevedo Porto Filho foi derrotado ao concorrer para o cargo de prefeito. Antes da família Azevedo, o município de Trairi esteve dominado pela família Ribeiro desde a década de 1950, que ficou à frente do município por quatro mandatos;

12) o clã familiar do ex-deputado Tomás Antônio Brandão, deputado estadual por sete (7) mandatos e líder do PSDB, além de ter sido prefeito de São Benedito em 1972, antes de seu primeiro mandato no Legislativo Estadual. Tomás Brandão é sobrinho de Francisco Júlio Filizola, deputado estadual (1955 a 1958) e também prefeito da mesma cidade, exercendo o cargo por 12 anos. Embora não tenha persistido na legislatura estadual, Filizola influiu na eleição do sobrinho Tomás Brandão e fez outro também prefeito: Paulo Roberto Filizola (1988 a 1992). A mulher de Tomás Brandão, Simone de Freitas Brandão, foi vice-prefeita no período de 2000 a 2006; o filho João Almir Freitas Brandão, falecido em 1998, foi eleito para o mandato no executivo em 1996; e o outro, Tomás Antônio Brandão Júnior, foi eleito mais recentemente em 2008. Outro mandato de prefeito esteve nas mãos do clã, José Hudson Filizola, eleito em 1992;

13) deputado Pedro Timbó, de Tamboril. Foi deputado estadual em quatro mandatos consecutivos, de 1991 a 2006. A administração da cidade de Tamboril esteve sob o controle de sua família por vinte e oito anos. Por exemplo, o seu irmão Francisco Timbó Camelo foi prefeito em quatro mandatos (1976, 1988, 1996 e 2000). Intercalando esses mandatos, esteve uma tia, Julieta Alves timbó, eleita em 1982.

\subsection{CONSIDERAC̣ÕES FINAIS}

Em um contexto democrático, com condições mais livres para a escolha de nossas representações políticas e para conquistas de direitos e políticas sociais, impressionam os dados que apontam para a permanência do controle político de 
administrações municipais por parte de clãs familiares, bem como sua transcendência para a política estadual. E isto ocorre em termos muito amplos, como já revelam os dados apresentados a partir das amostras de municípios nas eleições para prefeito, como o próprio quadro de deputados estaduais que marcam presença na Assembleia Estadual desde a década de 1970.

Esta pesquisa, embora considere apenas a realidade do estado do Ceará, já nos permite ter uma clara compreensão de que a cultura política brasileira, marcada pelo clientelismo e o patrimonialismo, está associada a essa dominância política. Com isto, ficam prejudicadas as possibilidades de conquista e de fortalecimento da própria cidadania e de superação das desigualdades políticas, sociais e econômicas.

Nosso esforço, ao concluir esse levantamento das eleições municipais e estaduais do Ceará contemporâneo, é o de investigar como se combina essa dominância eleitoral dos clãs familiares com o desempenho da política de assistência social em alguns municípios a serem selecionados, o que será realizado em outra pesquisa. Em outros termos, interessa-nos não apenas conhecer um quadro geral da política cearense com essa característica da dominância de clãs familiares, mas também avançar na análise de como isto influi no desenvolvimento de uma política social que tradicionalmente serviu de moeda nas trocas políticas.

\section{REFERÊNCIAS}

ASSEMbléIA LEGISLATIVA DO ESTADO DO CEARÁ. Memorial Deputado Pontes Neto. Deputados Estaduais 18 Legislatura 1971-1974. Fortaleza: INESP, 1999.

. Memorial Deputado Pontes Neto. Deputados Estaduais 19º Legislatura 1975-1978. Fortaleza: INESP, 2000.

. Memorial Deputado Pontes Neto. Deputados Estaduais 20 Legislatura 1979-1982. Fortaleza: INESP, 2002.

. Memorial Deputado Pontes Neto. Deputados Estaduais 21ํㅡㄹ Legislatura 1983-1986. Fortaleza: INESP, 2003.

. Memorial Deputado Pontes Neto. Deputados Estaduais 22 Legislatura 1987-1990. Fortaleza: INESP, 2004.

. Memorial Deputado Pontes Neto. Deputados Estaduais 14 Legislatura 1955-1958. Fortaleza: INESP, 2006.

. Memorial Deputado Pontes Neto. Deputados Estaduais 15º Legislatura 1959-1962. Fortaleza: INESP, 2006.

. Memorial Deputado Pontes Neto. Deputados Estaduais 23º Legislatura 1991-1994. Fortaleza: INESP, 2006.

BARREIRA, César. Trilhas e atalhos do poder: conflitos sociais no Sertão. Rio de Janeiro: Rio Fundo, 1992. 
BURSZTYN, Marcel. O poder dos donos: planejamento e clientelismo no Nordeste. 2. ed. Petrópolis: Vozes, 1985.

FAORO, Raymundo. Os donos do poder: formação do patronato político brasileiro. 3. ed. rev. São Paulo: Globo, 2001.

FARIAS, Airton. História do Ceará. 6. ed. rev. e ampl. Fortaleza: Armazém da Cultura, 2012.

LAVAREDA, Antonio. A democracia nas urnas: o processo partidário-eleitoral brasileiro, 1945/1964. 2. ed. rev. Rio de Janeiro: Iuperj: Revan, 1999.

LEAL, Victor Nunes. Coronelismo, enxada e voto: o município e o regime representativo no Brasil. 3. ed. Rio de Janeiro: Nova Fronteira, 1997.

LEMENHE, Maria Auxiliadora. Família, tradição e poder: o (caso) dos coronéis. São Paulo: Annablume: UFC, 1995. (Selo Universidades, v. 44).

MATOS, Francisco José Lima; ALCÂNTARA, Sérgio V. Sousa; DUMMAR, Wânia Cysne (Org.). Cenários de uma política contemporânea. Fortaleza: Fundação Demócrito Rocha, 1999.

MARINHO, Cristiane Maria. Pensamento pós-moderno e educação na crise estrutural do capital. Fortaleza: EdUECE, 2009.

MARTINS, José de Souza. O poder do atraso: ensaios de sociologia da história lenta. São Paulo: Hucitec, 1994.

MOTA, Aroldo. História política do Ceará. 1947-1966. Rio de Janeiro; São Paulo: ABC, 2005.

NOBRE, Maria Cristina de Q. O Estado na ordem do capital: o significado e o alcance das mudanças na "Era Tasso”. Dissertação de Mestrado. Fortaleza: UFC, 1999.

. Estado capitalista, lutas políticas e eleições: uma análise com Gramsci. Revista de Ciências Sociais, Fortaleza, v. 35, n. 2, 2004, p. 71-83.

- Modernização do atraso: a hegemônica burguesa do CIC e as alianças eleitorais da "Era Tasso". Tese de Doutorado. Fortaleza: UFC, 2008.

OLIVER COSTILLA, Lucio Fernando; NOBRE, Maria Cristina de Q. Dominação e hegemonia burguesa na transnacionalização do capital: o Ceará na "Era Tasso". Fortaleza, EdUECE, 2011.

REES, Laurence. Vende-se política. Rio de Janeiro: Revan, 1995.

SANTOS, Arnaldo; LEITÃO, Juarez. Verbo Cívico: visão histórico-sociológica da Assembléia Legislativa do Ceará. Fortaleza: Expert, 2002.

SANTOS, Wanderley Guilherme. O ex-Leviatã brasileiro: do voto disperso ao clientelismo concentrado. Rio de Janeiro: Civilização Brasileira, 2006.

\section{SITES CONSULTADOS}

SOARES, Afranio. Dr. Francisco Rocha Aguiar. Portal de Notícias Aconteceu Ipu.

Disponível em: <http://afraniosoares.blogspot.com.br/2010/05/dr-francisco-rocha-aguiar. 
html>. Publicado em: 19 maio 2010. Acesso em: 3 jul. 2012.

CHICO VAULINO SERIA REELEITO, MAS IBOPE APONTA EQUILÍBRIO.

Diário do Nordeste. Disponível em: <http://diariodonordeste.globo.com/materia. asp?codigo =569272>. Publicado em 4 set. 2008. Acesso em: 3 jul. 2012.

CARNAUBAL (CEARÁ). Wikipédia. Disponível em: <http://pt.wikipedia.org/wiki/ Carnaubal_\%28Cear\%C3\%A1\%29>. Acesso em: 3 jul. 2012.

NOMES E HISTÓRICO. Assembleia Legislativa do Estado do Ceará. Disponível em: $<$ http://www.al.ce.gov.br/index.php/deputados/nomes-e-historico/20-partidos/pdt/111>. Acesso em: 3 jul. 2012. 